International Journal of Engineering \& Technology, $7(2.8)(2018) 529-532$
International Journal of Engineering \& Technology
SPC
Website: www.sciencepubco.com/index.php/IJET
Research Paper

\title{
Band notched self complementary ultra wideband antenna for wireless applications
}

\author{
Ch. Ramakrishna ${ }^{1 *}$, G.A.E. Satish Kumar², P. Chandra Sekhar Reddy ${ }^{3}$ \\ ${ }^{1}$ Scholar JNTUH, Assistant professor, Vardhaman College of Engineering \\ ${ }^{2}$ Professor in ECE, Vardhaman College of Engineering \\ ${ }^{3}$ Professor in ECE, JNTUH College of Engg. \\ *Corresponding Author Email: rahulvar434@gmail.com
}

\begin{abstract}
This paper presents a band notched WLAN self complementary ultra wide band antenna for wireless applications. The proposed antenna encounters a return loss $\left(\mathrm{R}_{\mathrm{L}}\right)$ less than $-10 \mathrm{~dB}$ for entire ultra wideband frequency range except band notched frequency. This paper proposes a hexagon shape patch, edge feeding, self complementary technique and defective ground structure. The antenna has an overall dimension of $28.3 \mathrm{~mm} \times 40 \mathrm{~mm} \times 2 \mathrm{~mm}$, built on substrate FR4 with a relative dielectric permittivity 4.4. And framework is simulated finite element method with help of high frequency structured simulator HFSSv17.2. the proposed antenna achieves a impedance bandwidth of $8.6 \mathrm{GHz}$, band rejected WLAN frequency range $5.6-6.5 \mathrm{GHz}$ with vswr is less than 2 .
\end{abstract}

Keywords: Ultra wideband Antenna (UWB), self complementary, hexagon shape patch, Impedance Bandwidth, VSWR.

\section{Introduction}

Microstrip antennas are able to produce directional and Omni directional radiation patterns with larger bandwidths. And it also have one major limitation is their narrow bandwidth characteristic. Researchers have been engaged in remaining this limitation for the past 20 years and have been successful in achieving an impedance BW of up to 90 percentage and gain bandwidth up to 70 percentages [1-10].

Ihe input impedance of a patch antenna is found to varies with frequency, thus limiting the recurrence extend over which the feed line can be coordinated to its component. Non-linear analysis system applied in ultra wideband frequency operation [11-20]. Impedance data transmission of a fix reception apparatus is found to changes contrarily as quality factor $\mathrm{Q}$ of the fix receiving wire. substrate parameters , for example ,dielectric consistent $\varepsilon$ r and thickness $\mathrm{h}$ can be shifted to get distinctive quality factor. Eventually the expansion in Impedance data transmission.

Enhances in substrate height and decreases dielectric constant $\varepsilon_{\mathrm{r}}$ can be used utilized to build the impedance data transfer capacity of the reception apparatus. It has been built up that different of the fix shapes have essentially bring down quality factor Q contrasted with others. Feeding techniques are used to realize higher bandwidths.

In this paper, the proposed antenna designed to get larger bandwidth, for that proposing different methods hexagon shape patch, edge feeding technique, self complementary technique with defective ground structure are used.

\section{Proposed Antenna Design}

A compact band notched self complementary ultra wide band antenna is composed with a dimensions of $2.83 \mathrm{~cm} \times 4 \mathrm{~cm} \times 2 \mathrm{~cm}$ on a FR4 substrate with a dimensions of $2.83 \mathrm{~cm} \times 4 \mathrm{~cm} \times 0.16$ $\mathrm{cm}$, a defective ground structure plane dimensions of $1.2 \mathrm{~cm} \times$ $1.0 \mathrm{~cm}$. In the proposed ultra wideband microstrip patch self complementary antenna important characteristic is the extremely large Impedance bandwidth. The antenna consists of hexagonal shape patch with a dimensions of $\mathrm{s}=8.84 \mathrm{~mm}, \mathrm{a}=15.314 \mathrm{~mm}$ and $\mathrm{A}=17.64 \mathrm{~mm}$. This hexagonal shape microstrip patch is one of the various shapes capable for circular polarization.

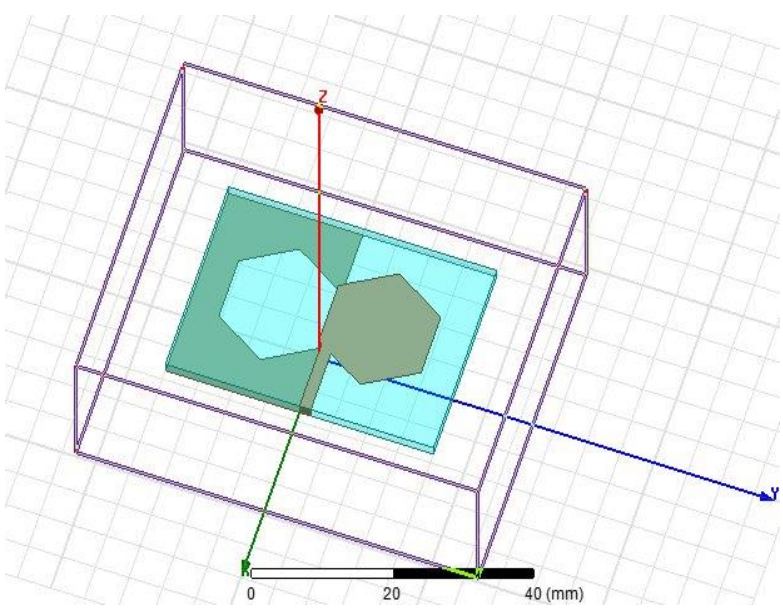

Fig. 1: The design of proposed self complementary UWB Antenna 


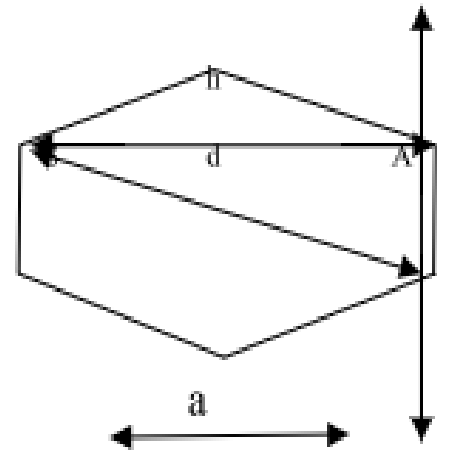

The hexagonal patch dimensions are $\mathrm{s}=8.84 \mathrm{~mm}, \mathrm{~A}=17.64 \mathrm{~mm}$, $\mathrm{a}=15.34 \mathrm{~mm}$ is feed through the micro-strip line with dimensions of $17.2 \mathrm{~mm} \times 1.7 \mathrm{~mm}$. the proposed band notched self complementary ultra wide band antenna resonates at a frequency of $10 \mathrm{GHz}$ with a fractional bandwidth of $95 \%$ is achieved frequency band range from $3.7 \mathrm{GHz}$ to $13.2 \mathrm{GHz}$ in this entire frequency range return loss is less than $-10 \mathrm{~dB}$. The maximum gain achieved is $4.59 \mathrm{~dB}$.In this quality factor $\mathrm{Q}$ of hexagon patch antenna as a function of the height and relative dielectric constant of the substrate respectively.

The Quality factor of a hexagonal patch increases almost linearly with the relative dielectric constant $\varepsilon_{r}$.in this hexagon patch modeling as a lossy capacitor, the increase in Q the energy stored increases and power radiated by the antenna will decrease by means of an increase in $\varepsilon$, likely when substrate width is increased, the decrease in storage energy diminish the Q quality factor. Because of fringing fields are increases with enhances in substrate height $\mathrm{h}$ and decrease in relative dielectric constant $\varepsilon_{\mathrm{r}}$, Thin substrate with higher relative dielectric constant is used for the proposed antenna for highly bound fields and to reduce the undesired radiation and coupling. In this structure hexagon patch correspond to as an arrangement of radiating slots, these slots detached by a low impedance $Z_{c}$. Because of the dimensions of hexagon patch are finite, the fields at the edges of the patch experiencing bordering impacts. The amount of bordering is an element of the measurements of hexagonal patch and tallness of the substrate $h$. The bordering fields are decreased appropriate choice, Proportion of the hexagon size to the tallness of the substrate it must be more noteworthy than the one.

\section{Results and Discussion}

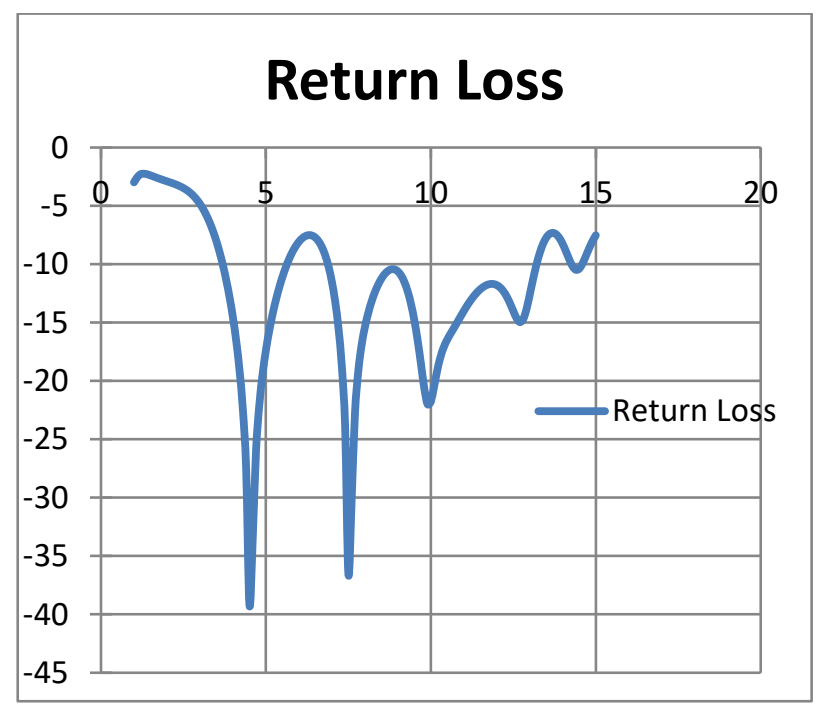

Fig. 2: The proposed antenna return loss

The impedance bandwidth of a patch antenna can be increased by establishing losses in the antenna, but at the disbursement of efficiency. This is losses can be in the form of lossy substrate materials. To achieve more impedance bandwidth antenna is designed on the FR4 substrate by relative dielectric constant 4.4 with 0.02 value of loss tangent. Figure 2 shows The proposed band notched self complementary ultra wide band antenna is achieved a bandwidth of $8.6 \mathrm{GHz}$ from $3.7 \mathrm{GHz}$ to $13.2 \mathrm{GHz}$ and band notched frequency range from $5.6 \mathrm{GHz}$ to $6.5 \mathrm{GHz}$ over a entire frequency range the gain of the system is more than the $2 \mathrm{~dB}$ except band notched frequency range gain is less.

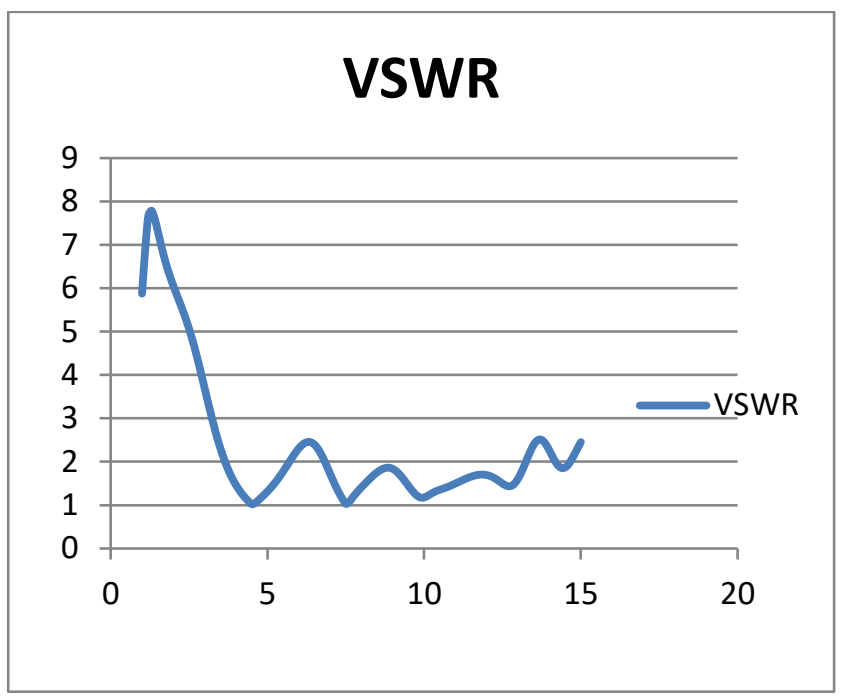

Fig. 3: The proposed antenna VSWR

Figure 3 shows the one of the important characteristics of a proposed antenna is voltage standing wave ratio (vswr). The vswr is always a real and positive number for antennas. VSWR is less, when the patch impedance is perfectly matched with the transmission line characteristic impedance and the antenna radiates maximum power into free space. Ideally an antenna VSWR be 1, it means that no reflected wave from the antenna. In this manuscript, the proposed band notched antenna hexagonal patch impedance is matched to the impedance of the micro-strip line to achieve a voltage standing wave ratio is less than the 2 except over a band rejected frequency commencing $5.5 \mathrm{GHz}$ to $6.5 \mathrm{GHz}$.

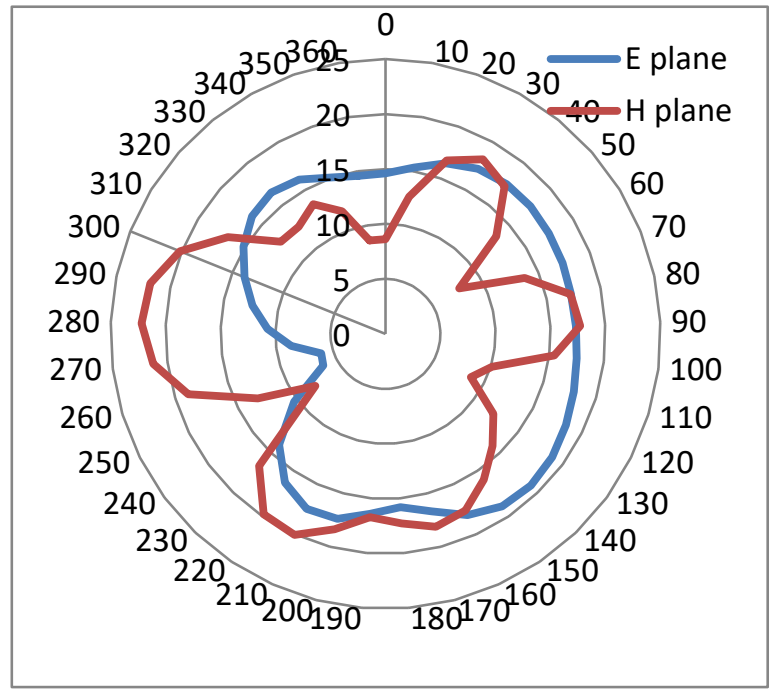

Fig. 4: The Proposed Antenna Radiation pattern

Figure 4 shows the proposed UWB Microstrip antennas Radiation patterns are analyzed in terms of a current source distribution on a Hexagonal patch and defective ground structure. For a proposed circularly polarized band notched antenna performance is often illustrated in terms of its principal $\mathrm{E}$ plane and $\mathrm{H}$ plane patterns. The principal E- Plane (elevation plane at $\mathrm{phi}=0 \mathrm{deg}$ ) containing 
the electric field vector, H-Plane (azimuthal plane at theta $=90 \mathrm{deg}$ ) contains the magnetic field vector is in the direction of maximum radiation.

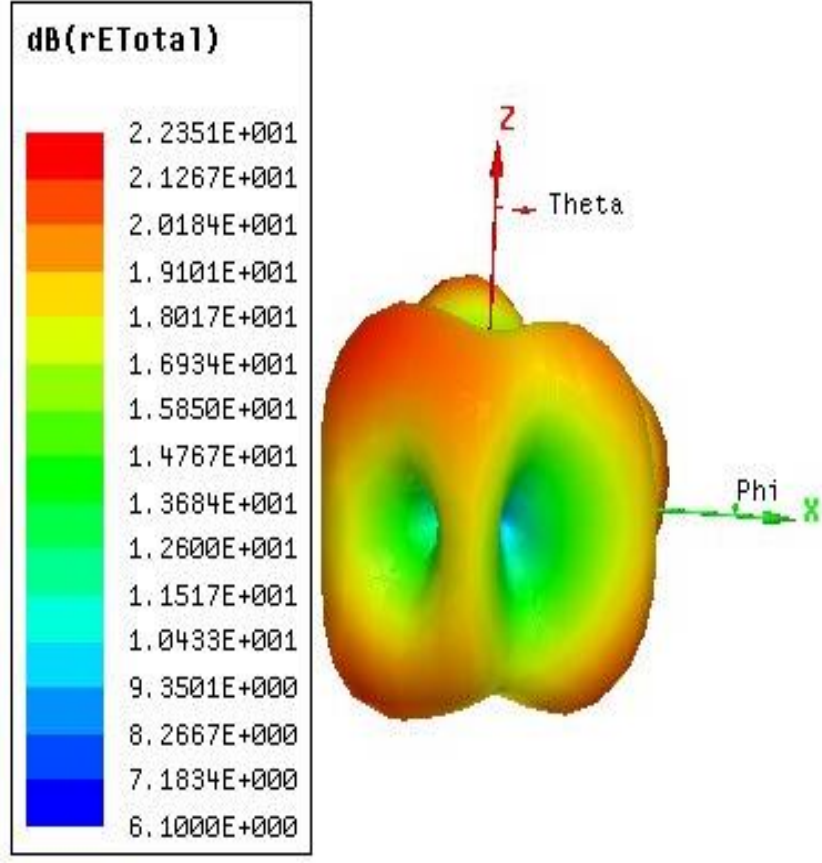

Fig. 5: Radiation pattern of the proposed antenna at $10 \mathrm{GHz}$.

The figure 5 shows the 3-D radiation pattern for the proposed band notched self complementary ultra wide band aerial.

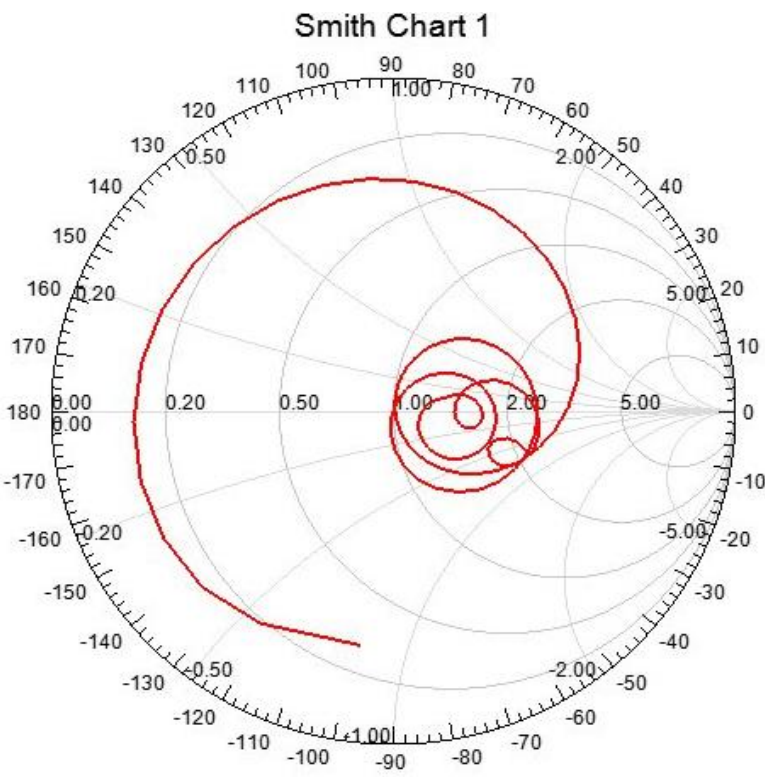

Fig. 6: Proposed band notched self complementary Antenna smithchart.

The smith chart is a polar plot of the reflection coefficient in terms of normalized impedance .mainly smith chart is used to measure normalized admittance from normalized impedance, vswr and reflection coefficient. Figure 6 shows the VSWR value of the proposed antenna, and it is observed that entire ultra wide band frequency range VSWR value is less than the 2 , and it is more than 2 for band rejected frequency bands.

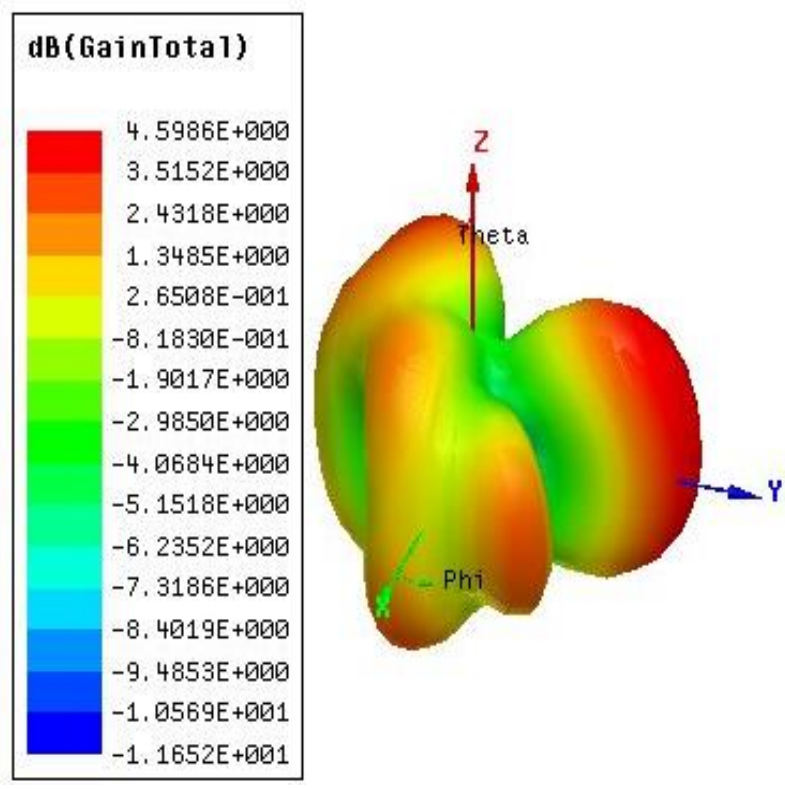

Fig. 7: Proposed antenna gain at $10 \mathrm{GHz}$

Figure 7 shows the gain of the proposed band notched self complementary antenna achieved $4.59 \mathrm{~dB}$ at $10 \mathrm{GHz}$ frequency, over entire frequency range gain is more than the 2 and very less value for the band notched frequency range.

\section{Conclusion}

An ultra wide band antenna eliminates the WLAN frequency band from $5.5 \mathrm{GHz}$ to $6.5 \mathrm{GHz}$. In this paper, Bandwidth of the antenna is increased by introducing edge feeding method, self complementary technique with defective ground structure. The designed antenna satisfies the return loss $<-10 \mathrm{~dB}$ entire UWB range. And it also achieves the gain except band rejected frequency range, fractional bandwidth of antenna is 95 percentage, efficiency is 87 percentage with a front- to- back ratio of 4.33 .

This proposed antenna is suitable for wireless communications with high data rate without disturbing the existing system WLAN By including slots in the hexagonal patch with different shapes, it can eliminate other wireless networks.

\section{References}

[1] James R.Kelly, Peter S.Hall, and Peter Gardner " Band - notched UWB antenna incorporating a microstrip open -loop resonator, "IEEE transaction Antennas propagation.,vol.59, pp.3045-3048, August 2011.

[2] Dong-Zo Kim, Wang-Ik Son, Won-Gyu Lim, Han-Lim Lee, and Jong Won $\mathrm{Yu}$, "Integrated planar monopole antenna with microstrip resonators having band-notched characteristics," IEEE transactions antennas propagation., vol.58, pp.2837-2842 2010.

[3] Qi Wu, Ronghong Jin, and Junping Geng "A Single- Layer Ultrawideband Microstrip Antenna" IEEE transaction on antennas and propagations, vol.58, no.1, January 2010

[4] A.P.S Pharwaha, J.Singh and T.S.Kamal, " Estimation of feed position of rectangular microstrip patch antenna," IE Journal-ET, volume 91, July 2010.

[5] N. Ghassemi J.Rashed-Mohassel M.H.Neshati "Slotted coupled microstrip antenna for ultra wide band applications in $\mathrm{C} \& \mathrm{X}$ bands" progress in Electromagnetics Research M,Vol.3,1525,2008

[6] Z.N.Chen, T.S.P.See, X.Qing, "small printed ultra wideband antenna with reduced ground plane effect", IEEE Transactions on Antennas and Propagation, vol.53, Feb 2007, pp.383-388.

[7] S.W.Su.K.L. Wong and C.L.Tang. " Band- notched ultrawideband planar monopole antenna," microw.Opt.Technol Lett, vol.44, pp.217-219, 2005. 
[8] G. Kumar , K.P.Ray, “ Broadband Microstrip Antennas,” Artech House antennas and propagation(2003)

[9] Pozar,D.M.," A Review of Bandwidth Enhancement Techniques for Microstrip Antennas," in Microstrip Antennas, The Analysis and design of Microstrip Antennas and Arrays, D.M.Pozar and D.H. schaubert (Eds),IEEE Press, New York, 1995, pp.157-166.

[10] Pozar, D.M.," Input Impedance and Mutual coupling of Rectangular Microstrip Antennas, “ IEEE Transaction Antennas and Propagations, Vol.AP-30, 1982, pp.1191-1196.

[11] R. Kalaivani, K. Ramash Kumar, S. Jeevananthan, "Implementation of VSBSMC plus PDIC for Fundamental Positive Output Super Lift-Luo Converter,” Journal of Electrical Engineering, Vol. 16, Edition: 4, 2016, pp. 243-258.

[12] K. Ramash Kumar,'Implementation of Sliding Mode Controller plus Proportional Integral Controller for Negative Output Elementary Boost Converter," Alexandria Engineering Journal (Elsevier), 2016, Vol. 55, No. 2, pp. 1429-1445.

[13] P. Sivakumar, V. Rajasekaran, K. Ramash Kumar, "Investigation of Intelligent Controllers for Varibale Speeed PFC Buck-Boost Rectifier Fed BLDC Motor Drive," Journal of Electrical Engineering (Romania), Vol.17, No.4, 2017, pp. 459-471.

[14] K. Ramash Kumar, D.Kalyankumar, DR.V.Kirbakaran” An Hybrid Multi level Inverter Based DSTATCOM Control, Majlesi Journal of Electrical Engineering, Vol. 5. No. 2, pp. 17-22, June 2011, ISSN: 0000-0388.

[15] K. Ramash Kumar, S. Jeevananthan, "A Sliding Mode Control for Positive Output Elementary Luo Converter," Journal of Electrical Engineering, Volume 10/4, December 2010, pp. 115-127.

[16] K. Ramash Kumar, Dr.S. Jeevananthan," Design of a Hybrid Posicast Control for a DC-DC Boost Converter Operated in Continuous Conduction Mode" (IEEE-conference PROCEEDINGS OF ICETECT 2011), pp-240-248, 978-1-4244$7925-2 / 11$

[17] K. Ramash Kumar, Dr. S. Jeevananthan," Design of Sliding Mode Control for Negative Output Elementary Super Lift Luo Converter Operated in Continuous Conduction Mode", (IEEE conference Proceeding of ICCCCT-2010), pp. 138-148, 978-1-4244-7768$5 / 10$.

[18] K. Ramash Kumar, S. Jeevananthan, S. Ramamurthy" Improved Performance of the Positive Output Elementary Split InductorType Boost Converter using Sliding Mode Controller plus Fuzzy Logic Controller, WSEAS TRANSACTIONS on SYSTEMS and CONTROL, Volume 9, 2014, pp. 215-228.

[19] N. Arunkumar, T.S. Sivakumaran, K. Ramash Kumar, S. Saranya, "Reduced Order Linear Quadratic Regulator plus Proportional Double Integral Based Controller for a Positive Output Elementary Super Lift Luo-Converter," JOURNAL OF THEORETICAL AND APPLIED INFORMATION TECHNOLOGY, July 2014. Vol. 65 No.3, pp. 890-901.

[20] Arunkumar, T.S. Sivakumaran, K. Ramash Kumar, "Improved Performance of Linear Quadratic Regulator plus Fuzzy Logic Controller for Positive Output Super Lift Luo-Converter,’ Journal of Electrical Engineering, Vol. 16, Edition:3, 2016, pp. 397-408.

[21] T. Padmapriya and V. Saminadan, "Priority based fair resource allocation and Admission Control Technique for Multi-user Multiclass downlink Traffic in LTE-Advanced Networks", International Journal of Advanced Research, vol.5, no.1, pp.1633-1641, January 2017.

[22] S.V.Manikanthan and D.Sugandhi "Interference Alignment Techniques For Mimo Multicell Based On Relay Interference Broadcast Channel " International Journal of Emerging Technology in Computer Science \& Electronics (IJETCSE) ISSN: 0976-1353 Volume- 7 ,Issue 1 -MARCH 2014. 